\title{
Partilhando informações durante catástrofes: experiências internacionais e 0 caso português fogos.pt
}

\section{Sharing information during catastrophes: international experiences and the Portuguese case of fogos.pt}

Fábio Ribeiro ${ }^{1}$

Resumo: Durante situações de emergência (inundações, sismos, incêndios etc.), o acesso a informação rigorosa pode ser decisivo para a segurança das pessoas. Atualmente, existem recursos digitais (sites, redes sociais e aplicações móveis) orientados para este sentido. Este artigo procura avaliar experiências dessa natureza, em países como o Japão, México, Espanha etc., através de uma amostra não probabilística, de uma análise de conteúdo manifesta e latente, e de uma entrevista semiestruturada com o responsável pelo projeto Fogos.pt, em Portugal. Os resultados sugerem que a troca de informações durante estes períodos varia entre o voluntariado e a contratualização de um serviço. Os contributos positivos dos cidadãos convivem frequentemente com campanhas de desinformação, destinadas a ludibriar a opinião pública e criar falsas campanhas de solidariedade. Palavras-chave: floresta; incêndios; média; cidadãos; participação.

Abstract: During emergencies (floods, earthquakes, fires, etc.), access to accurate information can be decisive to ensure people's safety. Some digital resources (websites, social networks and mobile applications) are currently geared towards this purpose. This article seeks to evaluate experiences of this nature, in countries such as Japan, Mexico, Spain, etc., through a non-probabilistic sample, a

1 Universidade do Minho (UM). Braga, Portugal; Universidade de Trás-os-Montes e Alto Douro (UTAD). Quinta de Prados, Vila Real, Portugal.

https://orcid.org/0000-0001-8071-6145 E-mail: fabior@utad.pt 
manifest and latent content analysis, and a semi-structured interview with the head of the Fogos.pt project in Portugal. The results suggest that the exchange of information during these periods varies between volunteering and contracting a service. Positive contributions from citizens often go hand in hand with misinformation campaigns aimed at misleading public opinion and creating false solidarity campaigns.

Keywords: forest; wildfire; media; citizens; participation. 


\section{Introdução}

A "Primavera Árabe”, designação atribuída a um conjunto de protestos iniciados em dezembro de 2010 e que culminaram na destituição de diversas figuras-chave de regimes autoritários no Egito, Líbia ou Líbano, surge frequentemente na linha da frente dos exemplos para demonstrar o impacto que o ecossistema digital - das sms às redes sociais - pode ter no espaço público. Contudo, a revista Wired ${ }^{2}$ fez o balanço do que se passou naqueles países do Médio Oriente e escreveu que as redes sociais permitiram a emergência destes fenômenos de protesto, mas não conseguiram salvar o povo das atrocidades do poder político que, entretanto, subiu ao poder. A Economist ${ }^{3}$ fez uma leitura totalmente distinta, sensivelmente pela mesma altura, em 2016, referindo que a tecnologia digital continuava a ser o garante da sobrevivência do espírito dos movimentos que estiveram na base da Primavera Árabe. No entanto, nem sempre as interpretações sobre estes fenômenos encerram leitura tão otimistas. Num estudo de Alhindi, Talha e Sulong considera-se que "os média tornaram-se inegavelmente numa ferramenta valiosa de organização dos protestos. Foram [os média] as plataformas de discussão por excelência e a informação era rapidamente divulgada e a consciência pública devidamente alertada" (2012, p. 107).

Como se pode depreender a partir deste exemplo, as interpretações nem sempre se tornam unívocas quando se pretende analisar com rigor e exatidão o poder emancipatório da tecnologia no quotidiano, aplicado a situações específicas. Em algumas áreas o papel da comunicação tem-se destacado na dinamização de novas rotinas sociais ou, no limite, de alterações substanciais na vida de determinados grupos ou comunidade. Este tem sido o caso da Comunicação para o Desenvolvimento, um ramo específico das Ciências da Comunicação, que tem vindo a agregar, num trajeto recente, diversas contribuições de âmbito teórico, mas sobretudo de natureza empírica e demonstrativa, este mesmo

2 Retirado de: https://www.wired.com/2016/01/social-media-made-the-arab-spring-but-couldnt-save-it/

3 Retirado de: https://www.economist.com/erasmus/2016/05/25/

digital-technology-is-keeping-the-spirit-of-the-arab-spring-alive 
desempenho da comunicação como revulsivo da ação humana. Como se pode comprovar em diversas publicações científicas, muitos destes estudos incidem preferencialmente em áreas rurais e as escassas contribuições sobre a tecnologia neste enquadramento social. Na revista Community Development, pode verificar-se, num dos últimos números (volume 49, n 3, de 2018), a ausência de referências a trabalhos sobre tecnologia. Observa-se estudos sobre a ligação entre cidades rurais nos EUA, processos de urbanização em Lagos (Nigéria) ou até mesmo empreendedorismo social no Peru. Na revista Community Development Journal, da Oxford Academic, constata-se a mesma escassez de integração da tecnologia neste tipo de estudos acadêmicos.

\section{A comunicação durante situações de catástrofe: linhas conceptuais}

O discurso público, enraizado nas relações sociais quotidianas e vinculado aos meios de comunicação social, utiliza frequentemente diversas expressões que procuram definir uma situação anômala, inesperada ou exasperante. Termos como catástrofe, crise ou emergência, entre tantos outros, surgem como tentativa de sintetizar acontecimentos que envolvem algum nível de gravidade ou emotividade. No entanto, do ponto de vista acadêmico e para as instituições oficiais, a distinção não parece ser tão simplista. Por exemplo, a Lei de Bases de Proteção Civil, em Portugal, define uma catástrofe nos seguintes termos: "é o acidente grave ou série de acidentes graves suscetíveis de provocarem elevados prejuízos materiais e, eventualmente vítimas afetando intensamente as condições de vida e o tecido socioeconômico em áreas ou na totalidade do território nacional" (TAPA, 2019, p. 25). Esta proposta, conforme recorda a autora, está em linha com a definição da própria Entidade Reguladora para a Comunicação Social (ERC).

Contudo, para diversos acadêmicos, catástrofe não é um sinônimo de crise (COOMBS, 2010; SEEGER, 2006; REYNOLDS, 2004), uma vez que se apresentam em planos e circunstâncias diferentes. Para Shaluf, Ahmadum e Said (2003, p. 1), “um desastre de origem humana 
que ocorra numa organização industrial pode evoluir para uma crise industrial". Bittar (2012) defende que é a magnitude que os eventos assumem que os tornam em crises, nomeadamente se estes acontecimentos recolhem a atenção generalizada e persistente dos média. Uma crise afeta a reputação institucional de uma organização, com inevitáveis consequências junto da opinião pública (AN \& GOWER, 2009), uma autêntica instituição aberta 24 horas por dia, em permanente efervescência e agitação (LIPPMANN, 1922). Neste panorama lexical difuso, surge a ideia de "risco", ampla e diversificada, embora aparentemente menos problemática numa espiral de efeitos, mas envolvendo emoções, perceções e até movimentos sociais (ULMER, SELLNOW, \& SEEGER, 2011, PETRIDOU et al., 2019).

Em termos corporativo e empresarial, a preocupação pela temática da gestão de crises surge também com alguma frequência. A Deloitte, em parceria com o Instituto Brasileiro de Relações com Investidores (IBRI), lançou o Manual de Gestão de Crises para Relações com Investidores Comunicação e estratégia para a preservação de valor em que apresenta três conceitos evolutivos dos eventos negativos que podem afetar as organizações empresariais. Neste sentido, apresenta a ideia de "problema", associado a pequenas situações do dia a dia, facilmente ultrapassáveis e sem repercussões públicas. Em seguida, surge o conceito de "incidente/emergência", que a Deloitte define como "fatos ou eventos que não fazem parte da operação padrão de um serviço e que podem causar uma interrupção ou a redução na qualidade do serviço (...) por um algum período de tempo" (2015, p. 5). Neste esquema conceptual gradativo, surge, por fim, a "crise", pensada "como qualquer evento ou percepção negativa que possa trazer danos à imagem da organização ou prejudicar seu relacionamento com a sociedade, clientes, acionistas, investidores, parceiros, órgãos reguladores, poderes públicos e demais partes interessadas" (2015, p. 5). Embora pouco exemplificada, esta proposta distingue-se pela atribuição de complexidade a um evento inesperado numa espiral de acontecimentos. Para efeitos deste trabalho, 
utilizaremos apenas o conceito de "crise", como lógica que resulta de uma catástrofe inicial.

Como já se referiu, a entrada triunfal da tecnologia no quotidiano (MARTINS, 2011) desafiou as condições pelas quais a sociedade entendia como garantidas as formas habituais de relacionamento, de acesso e partilha da informação (DETONI, 2015). Consequentemente, promoveu-se uma discussão mais sistematizada sobre a integração do cidadão em diversas áreas sociais. No entanto, não é líquido considerar-se que a promoção da participação do público apenas foi motivada pela emergência e consolidação definitiva da técnica no espaço público. Como recorda Valente (2013), é possível identificar alguns exemplos de intervenção específica do público no planeamento urbano (FORESTER, 1987), no desenvolvimento rural (WARBURTON, 1997) ou ainda na gestão do risco ambiental (GAMPER \& TURCANU, 2009), uma das áreas que este trabalho procura dar sequência. Weick (1995), numa frase provocativa, questiona até se o bom senso começa no caos.

Circunscrevendo o âmbito desta reflexão ao caso dos incêndios florestais, considera-se o fogo, do ponto de vista histórico, como uma arma de guerra, destinada a destruir inimigos através da propagação do terror (BESENYÖ, 2017). Nos países mediterrâneos, o fogo é, com larga distância, o fator principal pela destruição da floresta (KARANIKOLA, TAMPAKIS \& PAPALINARDOS, 2011). A rápida devastação causada por incêndios levanta questões sobre as informações que são trocadas, por entidades públicas e privadas responsáveis pela gestão do espaço florestal, para gerir da melhor maneira o fluxo de informações que se partilham sobre a evolução de uma determinada área ardida. Em áreas urbanas, de grande concentração populacional e do poder político, simbólico e mediático, existem, na teoria, maiores condições para uma cobertura mediática mais destacada, ao contrário daquela que sucede em zonas rurais, e mais afastadas dos grandes centros habitacionais. É provavelmente, nestes contextos que a informação sobre incêndios desde um ponto preventivo até ao desenrolar dos acontecimentos em 
tempo real - assume uma importância especialmente sensível. Contudo durante o desenrolar de incêndios, os média promovem juntos dos públicos, ainda que indiretamente, um sentimento de participação direta nos acontecimentos, com informações apuradas e diretas, que lhe podem induzir, erradamente, a sensação de que, aparentemente, tudo se sabe sobre um determinado incêndio (KARANIKOLA, TAMPAKIS, ARABATZIS \& MAHERIDIS, 2013). Tal como diversos estudos observam, os média praticamente negligenciam a publicação de conteúdos que refletem a necessidade de uma atitude preventiva perante os fogos ou de ações específicas de aconselhamento junto desta matéria. Segundo um estudo desenvolvido por Jacobson, Monroe e Marynowski (2001), da totalidade dos artigos publicados pelos grandes jornais americanos apenas 19\% introduzem alguma questão relativa à prevenção de incêndios. Num estudo semelhante, Paveglio et al. (2011) concluíram que nem em termos locais, com os meios de comunicação social de proximidade, o panorama se altera. Estes fatos pouco preocupa os cidadãos, na verdade. De acordo com Karanikola et al. (2011), as pessoas tendem a responder de forma mais consistente aos avisos de emergência se confiam verdadeiramente na fonte de informação, mais do que propriamente informações que possam ler em panfletos ou artigos de jornal.

Ora, do ponto de vista conceitual, a resposta que os cidadãos podem dar a um evento traumático como os incêndios, difere na leitura que alguns acadêmicos fazem do mesmo fenômeno (RIBEIRO, 2017). Em termos gerais, consideramos esta reposta nos termos em que, perante um incêndio, que pode eventualmente afetar direta ou indiretamente um ou mais cidadãos, relativamente à partilha de informação, em ambiente mediático. Chatfield, Scholl \& Brajawidagda (2014) utilizam a expressão Exchange during extreme events, Sandra Valente (2013) prefere o termo stakeholder participation para definir a mesma realidade. Whittaker, McLennan \& Handmer (2015) referem-se às "ações dos cidadãos durante emergências e desastres", Taylor et al. (2007) designam-na por “informação de acesso para evacuar". No entanto, a implicação aos média não aparece propriamente nas definições enumeradas. Correndo o 
riso de, eventualmente, esta análise não incluir outros conceitos que integrem a esfera mediática neste contexto, a participação dos cidadãos, durante catástrofes, e na perspetiva dos média integra, a nosso ver, diversas ações:

Tabela 1 - Tipologias de participação perante situações de emergência natural.

\begin{tabular}{lll}
\cline { 2 - 3 } & \multicolumn{1}{c}{ Tipologia de participação } \\
\cline { 2 - 3 } & \multicolumn{1}{c}{ Ativa } & \multicolumn{1}{c}{ Passiva } \\
\hline & $\begin{array}{l}\text { Produção e publicação } \\
\text { de conteúdos próprios }\end{array}$ & $\begin{array}{l}\text { Acompanhar o fluxo } \\
\text { informativo }\end{array}$ \\
$\begin{array}{l}\text { Comportamentos/ } / \\
\text { açes }\end{array}$ & $\begin{array}{l}\text { Interação nas redes sociais } \\
\text { e sites }\end{array}$ & $\begin{array}{l}\text { Partilhar com familiares } \\
\text { (sem qualquer meio de } \\
\text { comunicação associado) }\end{array}$ \\
& $\begin{array}{l}\text { Partilhar com familiares } \\
\text { (sem qualquer meio de } \\
\text { comunicação associado) }\end{array}$ & \\
\hline
\end{tabular}

Fonte: Autoria própria.

Em traços gerais, a promoção da participação ativa perante situações de catástrofe natural, como os incêndios, pretende desenvolver uma estratégia responsável dos cidadãos perante os recursos naturais, numa lógica de defesa das florestas de ameaças constantes de desaparecimento. A tomada forte de uma posição clara, neste sentido, poderá ainda transmitir a sensação de transparência, eficiência e responsabilidade junto das entidades que determinam o rumo das políticas públicas para com a floresta. A prevenção e a resposta aos riscos significariam, igualmente, um incremento na qualidade de vida, numa consciência de partilha de um espaço público comum.

\section{A tecnologia como resposta a situações limite}

Este trabalho discute a forma como a tecnologia de natureza social, interativa, eventualmente saberá responder a situações específicas em 
que os cidadãos enfrentem desastres naturais. Tomando como pretexto o caso dos incêndios, discute-se o potencial revulsivo da tecnologia, a predisposição dos cidadãos, o conhecimento ou ausência das mesmas possibilidades, e inclusive o grau de eficácia nas situações e nas considerações.

Seeger (apud TAPA, 2019) defende a necessidade de uma rede de contatos credível e operacionalizada antes de uma possível crise. "Para manter redes eficazes, os responsáveis devem continuar a validar fontes, escolher especialistas em áreas específicas e desenvolver relações com os stakeholders a todos os níveis", adverte Tapa (2009, p. 30). A coordenação das respostas a um problema deve envolver vários atores (HADDOW \& HADDOW, 2014; PALTTALA et al., 2012), que supõe um conhecimento antecipado dos papéis e funções que cada elemento desempenha neste processo operativo de resposta a situações problemáticas. No entanto, o problema persiste se este processo não chega aos cidadãos.

As tecnologias e as redes sociais modificaram substancialmente a resposta que as entidades e os cidadãos oferecem, na atualidade, a situações de catástrofe iminente ou em desenvolvimento. De acordo com Poblet, García-Cuesta \& Casanovas (2014), o Furacão Sandy, que em 2012 assolou diversas cidades na América do Norte, motivou um autêntico fluxo sem precedentes de conteúdos sobre a tempestade de mais de meio milhão de fotografias no Instagram e de 20 milhões de tweets, de entidades públicas e governamentais, organizações sem fins lucrativos, associações de voluntários e cidadãos em geral.

Em outubro de 2018, em Portugal, a tempestade tropical "Leslie" provocou uma série de estragos em diversas localidades da zona centro do país. Durante o sucedido, seis cidadãos decidiram criar o site VOST (Virtual Operations Support Team) Portugal, para informar a população, em tempo real, sobre as incidências que decorrem das situações de emergência no país ${ }^{4}$ : os tweets sobre a velocidade do vento, os locais

4 Disponível em: https://www.dn.pt/pais/interior/vost-portugal-nasceu-no-twitter-e-faz-aquilo-que-a-protecao-civil-devia-fazer-10003250.html?fbclid=IwAR2xG8jbLkhbfPptgfEgHJbPIY8 DSScOTPFZmGBlrw9XBMB9cUD-SloNlKI. 
mais vulneráveis, estradas cortadas, transportes públicos suprimidos, ajudar quem precisa de informações sobre familiares. "Em 12 horas alcançou mais seguidores do que o Twitter da Proteção Civil. Informações serviram de fonte às televisões e os voluntários conseguiram localizar pessoas incontactáveis. São seis pessoas que não se conhecem, mas se comunicam por um servidor utilizado em jogos online", referia a notícia. Os responsáveis pela VOST Portugal zelavam pela veracidade das informações recebidas. O objetivo consistia em fazer com que "a Proteção Civil arranjasse uma equipe que fizesse o que nós fazemos”, admite Jorge Gomes, um dos promotores.

Talvez por ter identificado alguns problemas na informação partilhada durante estas situações, a Entidade Reguladora para a Comunicação Social (ERC), em Portugal, lançou recentemente um guia de boas práticas para a cobertura de incêndios. Como noticiava o jornal Público5, os órgãos de comunicação social deveriam evitar o sensacionalismo, privilegiar o contato com fontes oficiais, evitando a exposição de imagens das vítimas.

\section{Metodologia}

Como forma de contribuir para uma reflexão que coloca os cidadãos e as tecnologias no epicentro do problema central deste artigo, este estudo utilizou duas técnicas de investigação: 1) a partir de uma amostra não probabilística por conveniência, pretende-se sinalizar um conjunto de iniciativas dinamizadas por cidadãos perante situações de iminente perigo, com o apoio de ferramentas e estratégias comunicativas digitais. Procede-se igualmente em conformidade com o entendimento de Bengtsson (2016), que propõe modelos de análise de fatos sociais e mediáticos com base em duas técnicas de análise: manifesta (o investigador retira conclusões a partir do discurso apresentado, numa análise tão próxima do texto quanto possível) e latente (o investigador avança para uma interpretação subjetiva do texto). Este artigo utiliza as duas formulações.

5 Disponível em: https://www.publico.pt/2018/07/19/politica/noticia/ erc-faz-guia-de-boas-praticas-para-cobertura-de-incendios-e-pede-menos-directos-183851 1. 
Privilegiou-se um critério geográfico diversificado, contemplando iniciativas da Oceania, Ásia, América e Europa; 2) a partir de um estudo de caso, na plataforma Fogos.pt, em Portugal, apresentam-se os resultados de uma observação não participante das dinâmicas associadas a esta iniciativa e de uma entrevista semiestruturada ao dinamizador desta iniciativa que representa, no panorama português, o exemplo de uma iniciativa gerada por cidadãos para a partilha de informações no decurso de situações de emergência associada a fenômenos naturais.

\section{Plataformas de partilha de informação}

Com efeito, na Tabela 2 observamos algumas experiências que servem de base a este estudo:

Tabela 2 - Amostra de experiências internacionais.

\begin{tabular}{ll}
\hline País & Iniciativa \\
\hline Canadá & Fire Smart Canada \\
Espanha & Ciclo Green \\
EUA & NFPA - Firewise USA \\
Japão & Nippon Volunteer Network Active in Disaster \\
México & Topos Tlatelolco \\
Nova Zelândia & Student Volunteer Army \\
\hline
\end{tabular}

Fonte: Autoria própria.

As diferentes iniciativas demonstram várias abordagens curiosas ao mesmo fenômeno de prevenção e gestão de informações durante catástrofes naturais, entendidas aqui numa perspectiva ampla.

Em primeiro lugar, a iniciativa Student Volunteer Army $(\mathrm{SVA})^{6}$, da Nova Zelândia. Trata-se de uma comunidade de jovens que desenvolvem esforços para apoiar a comunidade local na prevenção e na resposta a desastres naturais. Criada por Sam Johnson, um estudante da Universidade de Canterbury, na sequência do terremoto que se registou

6 Disponível em http://sva.org.nz. 
em Christchurch, em setembro de 2010, a ideia partiu da página do Facebook "Student Base for Earthquake Clean Up". Desde essa altura até a atualidade, o movimento apoiado essencialmente por estudantes tornou-se mais organizado. Através de um site observa-se campanhas de prevenção desenvolvidas, sobretudo em escolas, para públicos mais jovens. A SVA centraliza informação pertinente na resposta a cataclismos naturais.

No Japão, a Nippon Volunteer Network Active in Disaster $^{7}$ (NVNAD) apresenta traços bastante similares à iniciativa anteriormente apresentada. Organiza-se em torno de diversos voluntários que procuram dar uma resposta a eventos catastróficos que decorrem em solo nipônico. Nas intempéries que assolaram o Japão em julho de 2018, nomeadamente com as inundações naquele território, esta associação publicou diversas informações sobre as atividades que decorriam com o apoio dos colaboradores.

Na Espanha, o projeto Ciclo Green ${ }^{8}$, vinculado a algumas comunidades autônomas com o apoio do governo espanhol, oferecem opções de mobilidade aos cidadãos, através do aluguel de bicicletas que acumulam pontos para descontos na compra de determinados equipamentos desportivos, de bem-estar, acesso a visitas a espaços culturais, entre outras. No entanto, a aplicação, disponível em Android e iOS, é totalmente gratuita e permite o envio de informação geolocalizada para incêndios, por exemplo. Como refere o jornal El País ${ }^{9}$, a utilização da aplicação estende-se a 17 cidades espanholas, num total de 15 mil utilizadores, segundo dados de março de 2018.

As seguintes iniciativas introduzem, neste contexto, a dimensão comercial. A Fire Smart Canada organiza-se em torno de um serviço prestado às comunidades com um foco específico na questão ambiental, relacionado com a prevenção e gestão dos incêndios. Os cidadãos que aderem, através de um determinado pagamento, poderão usufruir de

7 Disponível em: http://www.nvnad.or.jp.

8 Disponível em: https:/www.ciclogreen.com/.

9 Disponível em: https://elpais.com/tecnologia/2018/03/13/actualidad/1520930098_046718. html. 
um conjunto de informações e serviços que vão desde ações de formação ambiental, gestão das vegetações próprias, aconselhamento legal e troca de informações sobre emergências que possam colocar em causa a segurança de habitações e cidadãos.

Nos Estados Unidos da América (EUA), a Fire Wise segue um modelo comercial praticamente idêntico ao exemplo anterior. Em coordenação com o Departamento de Floresta do governo americano, é oferecido um conjunto de serviços de proteção contra incêndios em moradias, e informações atualizadas sobre períodos. Nesta iniciativa, aparentemente, a contribuição dos cidadãos não parece revestir-se de grande protagonismo.

Por último, a iniciativa que se desenvolve essencialmente num espírito colaborativo com os cidadãos. O sismo de 8,1 na escala de Richter, em setembro de 1985, na Cidade do México, determinaria a criação, meses mais tarde, do movimento Topos Tlatelolco, uma brigada de ação rápida para o resgaste de pessoas em situações críticas. Mais de 30 anos depois do sucedido, a organização conta com mais de 200 voluntários que, através do site e das redes sociais, procuram atuar junto das populações em momentos de cataclismos naturais.

Em relação à interação digital das iniciativas assinaladas, a Tabela 3 identifica diversos níveis de atuação, entre sites, redes sociais e aplicações móveis.

Embora o propósito definidor deste estudo não inclua uma análise de conteúdo sobre a interação em sites, redes sociais e aplicações móveis, é possível identificar as dinâmicas digitais destas iniciativas. Em traços genéricos, os sites e aplicações móveis prestam-se ao simples propósito de apresentação do catálogo de atividades dinamizadas pelas variadas plataformas. Não existem propriamente espaços de interação entre utilizadores, embora a NFPA - Firewise (EUA) abra um separador específico no site para os internautas, mas sem qualquer registro de atividade. 


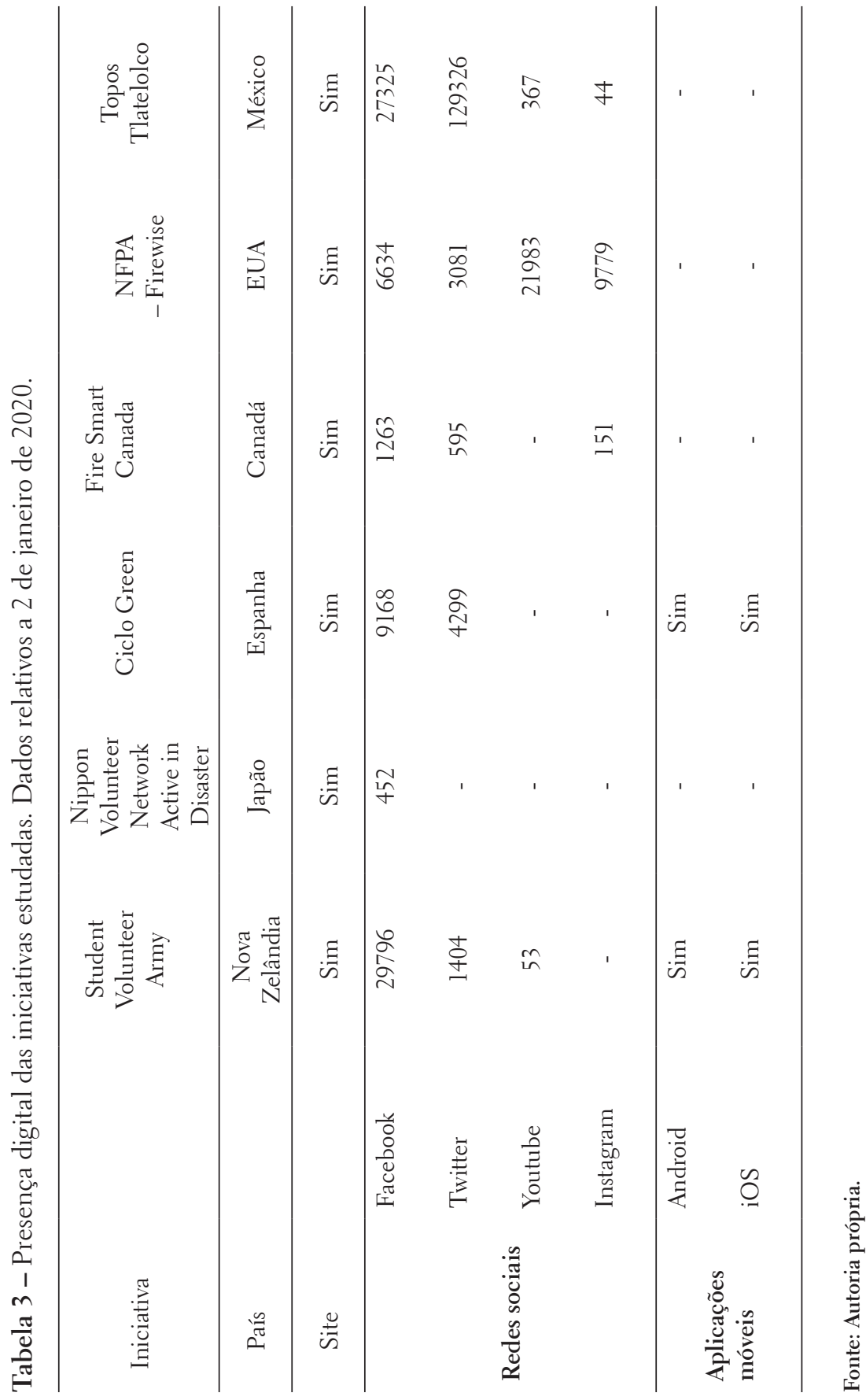


Todas as iniciativas consideradas nesta análise encontram-se ativas no Facebook. No entanto, a utilização desta ferramenta é díspar. A plataforma estudantil Student Volunteer Army (Nova Zelândia) é pouco ativa nesta rede, com uma média de um post por mês, tendo 2019 como referência, e não houve qualquer registro de aspecto problemático. As reações ou comentários aos posts são exíguos. A iniciativa japonesa Nippon Volunteer Network Active in Disaster demonstra uma intensa atividade no Facebook, sobretudo com as chuvas que se fizeram sentir no final de outubro de 2019, em Nagano, várias imagens elucidativas da passagem, mas com pouquíssimos comentários ou reações. Uma das publicações que mostra carros capotados, rastro de destruição, conta apenas com dois comentários agradecendo pelas imagens.

A NFPA - Firewise (EUA) e FireSmart Canada (Canadá) demonstram um elevado grau de atividade, mas dada a missão comercial das mesmas, procuram apenas apelar à atenção dos internautas para sessões práticas de formação sobre incêndios. A interação é quase nula.

No México, Topos Tlatelolco segue a mesma filosofia promocional, com publicações regulares, poucos comentários, apelos constantes a donativos, a participação dos sócios na assembleia daquela iniciativa. Em 2019, não há registo, por esta rede de qualquer incidente em que tenham participado.

A segunda rede social mais popular desta amostra é o Twitter. A atividade dos neozelandeses Student Volunteer Army é inconstante nesta rede, com poucas publicações em 2019. As plataformas NFPA - Firewise e FireSmart Canada repetem a postura de muita atividade para efeitos comerciais, mas com pouca interação.

Estas iniciativas praticamente negligenciam o papel dos vídeos, a principal característica identitária do Youtube. Apenas três (Student Volunteer Army, NFPA - Firewise e Topos Tlatelolco) das seis plataformas estudadas operam nesta rede, mas todas seguem uma atividade idêntica: poucos vídeos disponibilizados, fraca interação, numa espécie de montra audiovisual dos convívios entre os membros, pedidos de donativos ou venda comercial de serviços. 
Nas restantes redes, o panorama não é propriamente muito dinâmico. NFPA - Firewise e Topos Tlatelolco têm contas ativas no Instagram, embora o primeiro desenvolva a mesma atividade comercial e pouco interativa verificada nas outras redes e o segundo apenas tenha aderido a esta plataforma a 4 de dezembro de 2019.

\section{Estudo de caso: Fogos.pt}

A plataforma Fogos.pt ${ }^{10}$ destaca-se por ter sido uma das plataformas pioneiras na publicação de informações sobre situações de catástrofe em Portugal. Criada em agosto de 2015, por João Pina, engenheiro informático, trata-se de uma página web atualizada a todo instante com todas as informações sobre incêndios florestais. Segundo o responsável, Fogos.pt organiza uma informação que se "encontra dispersa" entre várias entidades públicas, como a Proteção Civil ou o Instituto Português do Mar e da Atmosfera, oferecendo uma informação sobre temperatura, pressão atmosférica, vento, precipitação, nuvens, descargas elétricas, que posteriormente se podem materializar em incêndios florestais. As informações colocadas nesta página são atualizadas a cada dois minutos, mostram uma localização aproximada dos referidos eventos, permitindo notificações no desktop sobre os incêndios em curso e os já extintos. A informação graficamente apresentada é apenas unidirecional, os utilizadores apenas podem trocar informações entre si nas redes sociais onde a iniciativa está presente, no Facebook ${ }^{11}$ e Twitter ${ }^{12}$. Existem também aplicações móveis para aceder a Fogos.pt, tanto para Iphone (IOS) quanto para smartphone (android). As seguintes imagens mostram parte da atividade do Fogos.pt.

10 Disponível em: http://fogos.pt.

11 Disponível em: http://www.facebook.com/fogospt.

12 Disponível em: http://twitter.com/fogospt. 
Figura 1 - Imagem de ecrã da plataforma Fogos.pt. Dados de 11 de junho de 2018. Entretanto, a plataforma sofreu alterações.

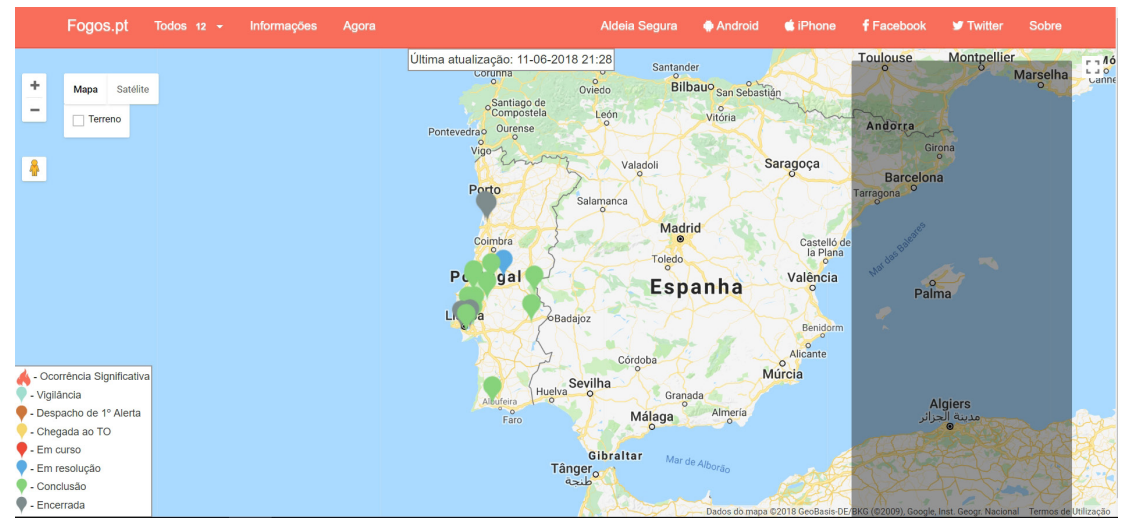

Fonte: Fogos.pt [imagem entretanto descontinuada]

Figura 2 - Versão atualizada da plataforma Fogos.pt. Dados de 20 de junho de 2018.

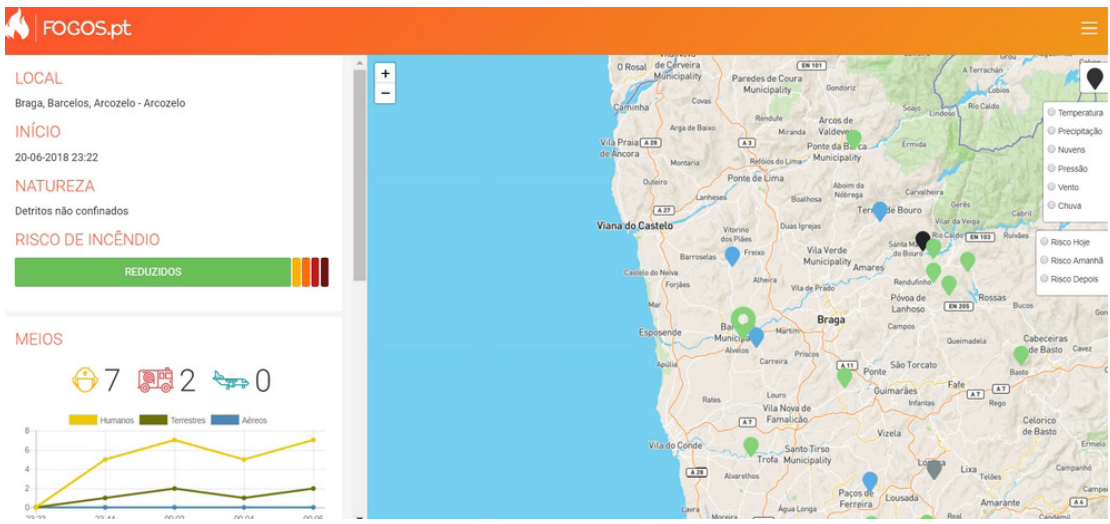

Fonte: Fogos.pt

O interesse mediático que Fogos.pt suscitou ${ }^{13}$ parece ser compatível com os números de acessos ao site que o responsável apresenta (Tabela 4):

13 Alguns exemplos: 1) https://shifter.sapo.pt/2017/10/app-incendios-em-portugal/; 2) https:// www.dn.pt/dinheiro/ha-fogo-no-seu-concelho-esta-aplicacao-vai-avisa-lo-10959482.html. 
Tabela 4 - Evolução no número de acessos ao site fogos.pt.

\begin{tabular}{lccc}
\cline { 3 - 4 } & & \multicolumn{2}{c}{ Tipo de acesso } \\
\hline Cronologia & Acesso online & Computador & Móvel \\
\hline agosto 2015 & 101 & $59 \%$ & $37 \%$ \\
agosto 2016 & 701 & $58 \%$ & $41 \%$ \\
outubro 2017 & 8.277 & $65 \%$ & $35 \%$ \\
\hline
\end{tabular}

Fonte: Fogos.pt.

Os números evidenciam um aumento expressivo nos acessos ao site num espaço de 2 anos, de pouco mais de 100 para mais de 8.000. Relativamente à origem da interação, os números mostram evoluções pouco significativas, ainda que se depreenda que o acesso através do computador $(65 \%)$ ainda seja bastante superior ao móvel (35\%).

Para compreender melhor algumas das dinâmicas desta iniciativa e dos problemas que diariamente são colocados, realizou-se uma entrevista semiestruturada ao responsável pelo site fogos.pt, por administração direta, via telefone. Esta técnica, segundo Quivy \& Campenhoudt, contribui "para descobrir os aspectos a ter em conta e alargam ou retificam o campo de investigação das leituras” (1992: 67).

João Pina começou por identificar que na gênese do site fogos.pt está o nível "desorganizado" e "problemático" da página online da Autoridade Nacional de Emergência e Proteção Civil (ANEPC). Para João Pina, a informação que consta no site da ANEPC "não corresponde muitas vezes com aquilo que está acontecendo no terreno, em termos do número de bombeiros, meios aéreos, veículos etc.”. Foi esta defasagem entre a realidade do combate aos incêndios e a informação disponibilizada aos cidadãos que motivou João Pina a criar esta plataforma online. Conforme se referiu anteriormente, este site agrega informação de diferentes entidades, desde a ANEPC ao Instituto de Meteorologia, ecrã que recupera a lógica habitual da pesquisa no Google Maps. A informação que surge nesta página é, como se referiu, unidirecional. Apenas nas redes sociais onde se encontra dinamizada a página fogos.pt é que os cidadãos podem efetivamente trocar informações entre si e cabe a João 
Pina transportá-las para o site, mediante a comprovação da sua veracidade. Para o responsável, existem diferenças de comportamento por parte dos utilizadores nas diferentes redes: “o Facebook ainda é a rede social mais popular em Portugal, ao contrário do Twitter. Nesta última, os utilizadores partilham informações mais concretas e diretas, que depois se traduzem em conteúdos mais verídicos e confiáveis". O caso do Facebook levanta mais problemas:

nessa rede temos uma situação específica que se repete inúmeras vezes. Muitas pessoas mandam-me mensagens que dão conta de diversas campanhas de recolha de alimentos, mantas, garrafas de água etc. para os bombeiros. Antes de colocar qualquer informação, preciso saber se é verdadeira e o que descubro facilmente é que $90 \%$ dessas campanhas são falsas, não existem. Muitas dessas corporações de bombeiros não pediram ajuda.

Admitindo diversos problemas que se relacionam com a autenticidade do conteúdo enviado pelos cidadãos, João Pina considera que a "boa participação existe na maioria das vezes". O entrevistado adianta que a partilha de conteúdos nestas situações pode ser decisiva, porque "por vezes, uma informação publicada há 4:00 horas não é propriamente atual e as pessoas precisam conhecer as informações naquele momento".

No caso português, a gestão da floresta tem estado na agenda política e mediática desde os incêndios de 2017, que, de junho a outubro, vitimaram mais de 100 pessoas no centro do país. Nessa altura, o site fogos.pt já existia. "Recebi milhares de mensagens nessa altura, porque as pessoas queriam saber o que estava acontecendo e havia muita falta de informação pertinente, apurada e verdadeira. As pessoas precisam saber para onde se dirige o fogo."

\section{Conclusões}

Este estudo parte do entendimento de que a segurança assume uma importância vital em termos de sociedade e nem sempre merece a reflexão que lhe deveria ser dedicada. Nesta complexa teia de atores, de públicos a privados, de informações confiáveis e outras francamente 
problemáticas, existem experiências no plano internacional que potenciam a troca de informações entre cidadãos durante períodos largos de incêndios florestais, inundações, entre outras circunstâncias. Tal como se verificou, anteriormente, estas possibilidades surgem, no contexto internacional, mediante a organização de esforços de cidadãos voluntários ou mesmo através de empresas que disponibilizam esse serviço comercial. Tal como se explorou neste artigo, a atividade digital - sites, redes sociais e aplicações móveis - das seis plataformas estudadas fica aquém daquilo que são as promessas emancipadoras da tecnologia. A presença digital surge apenas como um manifesto de presença, ausente de qualquer política própria de interação com os cidadãos, de diálogo permanente ou de apelo à consciência pública. Esta é uma das conclusões que surge inevitavelmente relacionada com a ausência de comentários, reações ou partilhas.

No caso português, a iniciativa Fogos.pt presta-se a um propósito de reorganização da informação dispersa no espaço digital, a partir do trabalho voluntário de um cidadão preocupado com estas questões. Esta experiência retoma, a partir das palavras do próprio dinamizador, algumas das principais debilidades que se colocam à interação digital neste ambiente: a pouca veracidade dos conteúdos e as tentativas de manipulação da opinião pública.

As principais limitações deste estudo apontam à amostra selecionada que, naturalmente, poderia ter incluído outras experiências no plano internacional. Na verdade, ainda se sabe pouco sobre o potencial revulsivo das tecnologias em períodos de catástrofe natural, especialmente aquelas que se referem às dinâmicas próprias dos cidadãos em partilhar informação durante estes períodos. Futuros projetos e trabalhos nesta área poderiam tentar compatibilizar estas duas agendas, através da inclusão de mais experiências onde a tecnologia serve de interação em momentos de crise e as práticas comunicativas dos cidadãos durante incêndios, inundações etc. Parece ainda ser vital a renovada aposta no estudo, por parte de acadêmicos, das fronteiras onde existe uma verdadeira sociologia da comunicação. 


\section{Referências}

ALHINDI, W.; TALHA, M.; SULONG, G. The Role of Modern Technology in Arab Spring. Archives Des Sciences, v. 65, n. 8, p. 101-112, 2012.

AN, S.; GOWER, K. How do the news media frame crises? A content analysis of crisis news coverage. Public Relations Review, n. 35, p.107-112, 2009. DOI: https://doi. org/10.1016/j.pubrev.2009.01.010.

BENGTSSON, M. How to plan and perform a qualitative study using content analysis. NursingPlus Open, n. 2, p. 8-14, 2016.

BESENYÖ, J. Inferno Terror: Forest Fires as the New Form of Terrorism. Terrorism and Political Violence, v. 31, n. 6, p. 1.229-1.241, 2017. DOI: http://dx.doi.org/10.1080/095 46553.2017.1341876.

BITTAR, D. O poder da assessoria de comunicação nos momentos de crise. 2012. Disponível em: http://www.bocc.ubi.pt/pag/bittar-danielle-o-poder-da-assessoria-de-comunicacao.pdf. Acesso em: 2 dez. 2019.

CHATFIELD, A.; SCHOLL, H.; BRAJAWIDAGDA, U. \#Sandy Tweets: Citizens' Co-Production of Time-Critical Information during an Unfolding Catastrophe. In: HAWAII INTERNATIONAL CONFERENCE ON SYSTEM SCIENCE, 47., 2014, Hawai.

COOMBS, W. T. The Handbook of Crisis Communication. Singapura: Graphicraft Limited, 2010.

DELLOITE. Manual de Gestão de Crises para Relações com Investidores Comunicação e estratégia para a preservação de valor. 2015. Disponível em: <https://www2.deloitte. com/content/dam/Deloitte/br/Documents/risk/Manual-Gestao-Crises-para-RI.pdf.

Acesso em: 2 set. 2019.

DETONI, M. Os meios públicos de comunicação e a construção da esfera pública. Comunicação e Sociedade, n. 30, p. 21-37, 2016.

FORESTER, J. Planning In the Face of Conflict: Negotiation and Mediation Strategies in local Land Use Regulation. Journal of American Planning Association, v. 53, n. 3, p. 303-314, 1987.

GAMPER, C.; TURCANU, C. Can public participation help managing risks from natural hazards? Safety Science, n. 47, p. 522-528, 2009.

HADDOW, G.; HADDOW, K. Disaster Comunication in a Changing Media World. Nova Iorque: Elsevier, 2014.

JACOBSON, S. K.; MONROE, M. C.; MARYNOWSKI, S. Fire at the wildland urban interface: The influence of experience and mass media on knowledge, attitudes, and behavioral intentions. Wildlife Society Bulletin, v. 29, v. 3, p. 929-937, 2001.

KARANIKOLA, P.; TAMPAKIS, S.; ARABATZIS, G.; MAHERIDIS, A. Study on citizens information about forest fires: the case of Kavala. Procedia Technology, n.8, p. 482-487, 2013.

KARANIKOLA, P.; TAMPAKIS, S.; MANOLAS, E.; PAPALINARDOS, I. The 2007 forest fires in the prefecture of Ilia: the views of citizens with regard to the actions taken 
before, during and after the fires. International Journal of Environmental Studies, v.68, n.5, p. 687-701, 2011.

LIPPMAN, W. Public opinion. Nova Iorque: Free Press, 1922.

MARTINS, M. Crise no castelo da cultura. Das estrelas para os ecrãs. Coimbra: Grácio Editor, 2014.

PALTTALA, P.; BOANO, C.; LUND, R.; VOS, M. Communication gaps in disaster management: Perceptions by experts from governmental and non-governmental organizations. Journal of Contigences and Crisis Management, v. 20, n. 1, p. 2-12, 2012.

PAVEGLIO, T.; NORTON, T.; CARROLL, M. S. Fanning the flames? Media coverage during wildfire events and its relation to broader societal understandings of the hazard. Human Ecology Review, v. 18, n. 1, p. 41-52, 2011.

PETRIDOU, E.; DANIELSSON, E.; OLOFSSON, A.; LUNDGREN, M.; GROßE, C. If Crisis or War Comes: A Study of Risk Communication of Eight European Union Member States. Journal of International Crisis and Risk Communication Research, v. 2, n. 2, p. 207-232, 2019. DOI: https://doi.org/10.30658/jicrcr.2.2.3.

POBLET, M.; GARCÍA-CUESTA E.; CASANOVAS P. Crowdsourcing Tools for Disaster Management: A Review of Platforms and Methods. In: CASANOVAS, P.; PAGALLO, U.; PALMIRANI, P. M.; SARTOR, G. (Ed.). AI Approaches to the Complexity of Legal Systems. AICOL 2013. Lecture Notes in Computer Science (p. 261-274). Berlim: Springer, 2014.

QUIVY, R.; CAMPENHOUDT, L. Manual de investigação em Ciências Sociais. Lisboa: Gradiva, 1992

REYNOLDS, B. Crisis and Emergency Risk Comunication. Atlanta: Centers for Disease Control and Prevention. 2014.

RIBEIRO, F. Opinião pública nos média em Portugal: quem participa e por quê? Braga: Centro de Estudos de Comunicação e Sociedade da Universidade do Minho, 2017.

SEEGER, M. Best Practices in Crisis Communication: An Expert Panel Process. Journal of Applied Communication Research, v. 34, n. 3, p. 232-244. 2006.

SHALUF, I.; AHMADUN, F.; MAT SAID, A. A review of disaster and crisis. Disaster Prevention and Management, v. 12, n. 1, p. 24-32, 2013.

TAPA, S. A comunicação de crise em situações de catástrofe: o caso do incêndio de Pedrógão Grande. 2019. 126 f. Dissertação (Mestrado em Ciências da Comunicação) - Escola Humana de Ciências Sociais, Universidade de Trás-os-Montes e Alto Douro, Vila Real, 2019.

TAYLOR, J. G.; GILLETTE, S. C.; HODGSON, R. W.; DOWNING, J. L.; BURNS, M. R.; CHAVEZ, D. J.; HOGAN, J. T. Informing the network: Improving communication with interface communities during wildland fire. Human Ecology Review, v. 14, n. 2, p. 198-211, 2007.

ULMER, R.; SELLNOW, T.; SEEGER, M. Effective crisis communication: Moving from crisis to opportunity. 2. ed.. Thousand Oaks: Sage, 2011.

VALENTE, S. Participação pública na gestão florestal sustentável em área afetadas por fogos. 2013. 534 f. Tese (Doutorado) - Universidade de Aveiro, Aveiro, 2013. 
WARBURTON, D. Participatory Action in the Countrysside: a Literature Review. Sheffield: Countryside Commission, 1997.

WEICK, K. Cosmos vs. chaos: sense and nonsense in electronic contexts. Organizational Dynamics, v. 14, n. 2, p. 51-64, 1995.

WHITTAKER, J.; MCLENNAN, B.; HANDMER, J. A review of informal volunteerism in emergencies and disasters: Definition, opportunities and challenges. International Journal of Disaster Risk Reduction, n. 13, p. 358-368, 2015.

\section{Sobre o autor}

Fábio Ribeiro - Professor Auxiliar do Departamento de Letras, Artes e Comunicação da Universidade de Trás-os-Montes e Alto Douro (UTAD), leciona nas áreas do Jornalismo (Rádio, Imprensa) e Sociologia da Comunicação. Completou o Doutoramento Europeu em Ciências da Comunicação, especialização em Sociologia da Comunicação, em 2013, na Universidade do Minho, depois de cumprir um período de atividades de formação complementar no grupo de investigação PUBLIRADIO, na Universidade Autónoma de Barcelona, em Espanha. Do ponto de vista da investigação, centra-se em temas como a interatividade entre cidadãos e os média, meios de comunicação de proximidade e comunicação de ciência. É sócio da Sopcom, onde é coordenador adjunto do Grupo de Trabalho "Rádios e Meios Sonoros", desde 2017, e da ECREA. Foi jornalista estagiário na TSF-Rádio Notícias, consultor de comunicação no setor empresarial e gestor de ciência e tecnologia.

Data de submissão: 22/05/2020

Data de aceite: 24/09/2020 